\title{
Endocrine changes from birth to puberty in the heifer*
}

\author{
S. E. Dodson, B. J. McLeod $\dagger$, W. Haresign, A. R. Peters $\ddagger$ and \\ G. E. Lamming
}

\begin{abstract}
A.F.R.C. Research Group on Hormones and Farm Animal Reproduction, University of Nottingham School of Agriculture, Sutton Bonington, Loughborough, Leics LE12 SRD, U.K. and $\ddagger$ M.L.C., Queensway House, Bletchley, Milton Keynes MK2 2EF, U.K.
\end{abstract}

\begin{abstract}
Summary. Twelve autumn-born Hereford $\times$ Friesian heifers were studied to characterize changes in the patterns of $\mathrm{LH}$ and FSH secretion occurring from birth through the peripubertal period. A once weekly blood sampling regimen, starting 3 days after birth, was combined with periods of frequent sampling (15-min intervals for $24 \mathrm{~h}$ ) every month from 3 weeks of age.

Mean plasma LH concentrations decreased over the period from birth to 15 weeks of age, largely due to a decrease in basal LH concentrations. Thereafter, mean plasma LH concentrations increased to 39 weeks of age, mainly as a consequence of increasing LH episode frequency and LH episode amplitude.

Oestrus was detected using an oestradiol-treated steer, and ovulation inferred from progesterone profiles. A 'short luteal phase' oestrous cycle preceded the first observed oestrus, and this was followed in all heifers by a normal length luteal phase. However, no increase in mean LH concentrations, basal LH concentrations, LH episode frequency, LH episode amplitude or change in mean FSH concentration could be directly associated with the onset of puberty. It is therefore concluded that the gonadotrophic stimulus for first ovulation must occur abruptly.
\end{abstract}

Keywords: puberty; heifers; LH; FSH

\section{Introduction}

The 'gonadostat' hypothesis has been advanced to explain the mechanism behind the onset of puberty (Ramirez \& McCann, 1963). The hypothesis is based on the observation that gonadotrophin secretion escapes from steroid hormone suppression at the pubertal age in ovariectomized animals given oestradiol implants (rat: Steel \& Weisz, 1974; sheep: Foster \& Ryan, 1979; heifer: Day et al., 1984). These observations are believed to indicate that the hypothalamic mechanism controlling gonadotrophin secretion in the immature animal is highly sensitive to the inhibitory effects of oestradiol. As puberty approaches, this sensitivity decreases, allowing gonadotrophins to rise to concentrations sufficient to stimulate follicular growth and hence produce the first ovulation. Although it is generally accepted that this hypothesis may be applicable to farm species, appropriate experimental results are limited. Conflicting data have been recorded for the heifer; some workers have reported that episodic LH release increases gradually from birth to puberty (Schams et al., 1981; Day et al., 1984), while others have been unable to detect such changes (GonzalezPadilla et al., 1975a; McLeod et al., 1984). The infrequent blood sampling regimen used in the study of Gonzalez-Padilla et al. (1975a) was inadequate to identify changes in episodic patterns of gonadotrophin secretion, and the use of only limited periods of frequent sampling (Schams et al.,

\footnotetext{
*Reprint requests to Dr W. Haresign.

$\Varangle$ Present address: Cattle and Sheep Production Department, A.F.R.C. Institute for Grassland and Animal Production, Animal Grassland Research Station, Hurley, Maidenhead, Berks SL6 5LR, U.K.
} 
1981; Day et al., 1984) could lead to inaccurate estimations of LH episode frequency. Furthermore, studies in the sheep may be confounded by the strong influence of season.

The aim of this study was to characterize in detail the pattern of gonadotrophin secretion from birth to puberty in the heifer with the long-term view of determining whether gonadotrophin secretion in the prepubertal heifer might be manipulated to induce premature ovulation.

\section{Materials and Methods}

\section{Animals}

Twelve autumn born Hereford $\times$ Friesian heifers were bought at 3 days of age, and reared on milk substitute at the School of Agriculture. After weaning at 7 weeks of age, they were maintained as a single group and fed a diet of concentrates and hay designed to produce a growth rate of $0.65 \mathrm{~kg} /$ day. The animals were housed indoors under conditions of natural daylength and temperature, until being turned out on to pasture at 31 weeks of age.

Collection of blood samples. Blood samples $(25 \mathrm{ml})$ for $\mathrm{LH}$ and FSH determinations were collected by jugular puncture, weekly from 3 days of age until after the completion of an oestrous cycle of between 18 and 22 days, reported to be the normal range for the heifer (Robinson, 1977). From 39 weeks of age until the onset of regular oestrous cycles, blood samples $(7 \mathrm{ml})$ were collected by jugular puncture 3 times weekly for progesterone analysis.

At 3 weeks of age all heifers were fitted with indwelling jugular vein catheters and restrained with halters. After a 12-h recovery period, blood samples for gonadotrophin analysis $(2 \mathrm{ml})$ were collected at 15 -min intervals for $24 \mathrm{~h}$. Night-time sampling was conducted under dim white light. Thereafter, this procedure was repeated at intervals of 4 weeks. From 37 weeks of age, prepubertal animals were selected according to their body weight $(>210 \mathrm{~kg})$, and after cannulation were blood sampled at 15 -min intervals for additional 8 -h periods. These sampling periods occurred at monthly intervals, mid-way between the 24-h sampling periods.

Monitoring of oestrous cycles. Oestrus was monitored from 27 weeks of age, by daily inspection for the removal of tail paste (Tel-Tail, ICI plc, Cheshire, U.K.). To aid this the heifers were run with an oestradiol-treated steer (Sawyer \& Fulkerson, 1981). The steer was injected i.m. at weekly intervals with a solution of oestradiol in ethyl oleate $(2 \mathrm{mg} / \mathrm{ml})$, at a dose of $8-10 \mathrm{mg} / 250 \mathrm{~kg}$ bodyweight, for 12 weeks. Thereafter oestradiol treatment was administered at 2-weekly intervals.

Hormone radioimmunoassay. Plasma concentrations of LH were determined by the specific homologous doubleantibody radioimmunoassay method of Webb et al. (1977). Within this study the limit of sensitivity of the assay was $0.33 \mathrm{ng} \mathrm{NIH-LH-B9}$ equiv./ml plasma and the inter- and intra-assay coefficients of variation were $7 \cdot 1 \%$ and $8 \cdot 8 \%$, respectively.

Plasma samples were assayed for FSH by the heterologous radioimmunoassay of Webb et al. (1980). The limit of sensitivity within this study was $11 \mathrm{ng}$ NIH-FSH-B1 equiv./ml plasma. Inter- and intra-assay coefficients of variation were $12.6 \%$ and $10 \%$, respectively.

Progesterone concentrations were measured in plasma by the extraction technique described by Webb et al. (1977), with the modifications of Hunter et al. (1986). The limit of sensitivity was $0 \cdot 1 \mathrm{ng} / \mathrm{ml}$ plasma, the mean extraction efficiency was $85 \pm 4.0 \%$ and both the inter- and intra-assay coefficients of variation were $<15 \%$.

Analysis of data. An LH episode was defined by the following criteria (a) an increase of at least $1 \mathrm{ng}$, representing an increase of $\geqslant 4$ times the intra-assay coefficient of variation of duplicate pairs above the preceding baseline value, (b) at least 2 points between the peak value and the succeeding trough or baseline, and (c) a rate of decline in concentrations after the peak no greater than that allowed by the known half-life of the hormone. The basal LH concentration was calculated as the overall mean LH concentration for a profile minus the LH episodes. LH episode amplitude was calculated as the maximum LH concentration reached.

Data were analysed using analysis of variance, with changes in hormone concentrations with time and their patterns being tested for significant linear and curvilinear trends. LH episode frequencies were tested by analysis of deviance, assuming a Poisson distribution.

A heifer was considered to be showing normal luteal function when an elevation in plasma progesterone concentration occurred within 4 days of the animal showing oestrus, reached a maximum of $>2.5 \mathrm{ng} / \mathrm{ml}$ and was elevated for at least 10 days.

\section{Results}

\section{Progesterone concentrations from birth}

In all animals, progesterone concentrations were undetectable until just before first oestrus. A small progesterone elevation of approximately 6 days duration (based upon the mean progesterone 


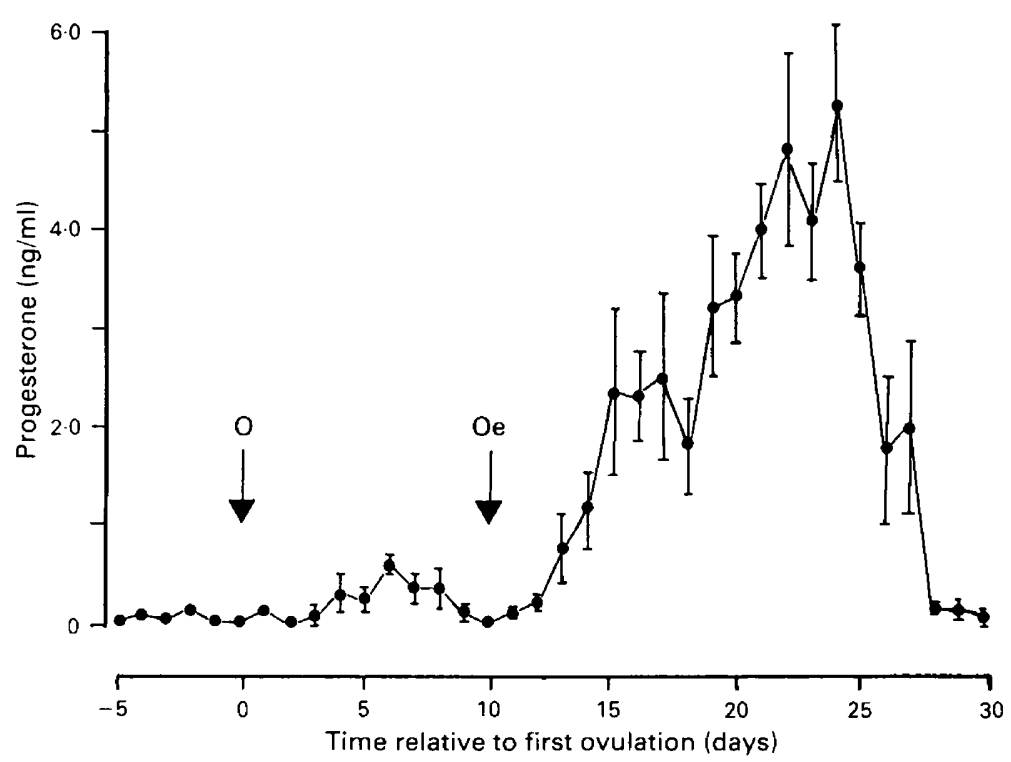

Fig. 1. Mean ( \pm s.e.m.) plasma progesterone concentrations of 12 heifers synchronized about the time of first oestrus. $\mathrm{Oe}=$ first oestrus, $\mathrm{O}=$ estimated time of first ovulation.

profile) preceded first oestrus in 10/12 heifers (Fig. 1). Ovulation was presumed to have occurred 4 days before this first progesterone elevation, and taken to represent puberty.

The mean age and weight at puberty were $318 \pm 11.7$ days and $249 \pm 5.4 \mathrm{~kg}$ respectively, and the first normal oestrous cycle was of a mean length of $19 \cdot 1 \pm 0.52$ days.

\section{Gonadotrophin data from birth}

As the heifers were all of the same age, gonadotrophin data were initially analysed, with respect to time, from the first sampling period onwards. This analysis was not continued beyond 39 weeks of age in order to minimize differences in physiological stages of maturity between animals. Thereafter LH and FSH data were standardized about the presumed prepubertal ovulation which preceded the initial short-lived rise in progesterone. $\mathrm{LH}$ data from the analysis of $24-\mathrm{h}$ profiles are shown in Fig. 2(a).

The overall mean plasma $\mathrm{LH}$ concentration decreased from 0.96 to $0.76 \mathrm{ng} / \mathrm{ml}$ between 3 and 15 weeks of age, increasing to $1.21 \mathrm{ng} / \mathrm{ml}$ by 35 weeks of age. The data showed significant linear $(P<0.001)$ and cubic $(P<0.01)$ trends. Basal LH concentrations showed significant quadratic and cubic trends (both $P<0.001$ ), decreasing from $0.94 \mathrm{ng} / \mathrm{ml}$ at 3 weeks of age to $0.55 \mathrm{ng} / \mathrm{ml}$ at 15 weeks of age, thereafter increasing to $0.71 \mathrm{ng} / \mathrm{ml}$ at 27 weeks of age with no further change through to 35 weeks of age.

LH episode frequency was lowest at 3 weeks of age, an episodic pattern of LH release being present in only $3 / 12$ heifers. By 7 weeks of age all heifers had an endogenous LH episode frequency of one or more episodes $/ 24 \mathrm{~h}$ which then increased following a significant linear trend $(P<0.01)$. The rapid increase in LH episode frequency between 3 and 7 weeks of age resulted in a significant quadratic component of change within the data $(P<0.001)$. Despite increasing in a linear fashion from 7 weeks of age, LH episode frequency at 35 weeks of age was still only approximately 5 episodes $/ 24 \mathrm{~h}$. The amplitude of LH episodes also increased linearly $(P<0.001)$ between 3 and 35 weeks of age (Fig. 2a).

FSH data from the analysis of 24-h profiles are shown in Fig. 2(b). Mean FSH concentrations showed a significant quadratic $(P<0 \cdot 01)$ change with time, decreasing from $40 \cdot 1 \mathrm{ng} / \mathrm{ml}$ at 3 weeks 

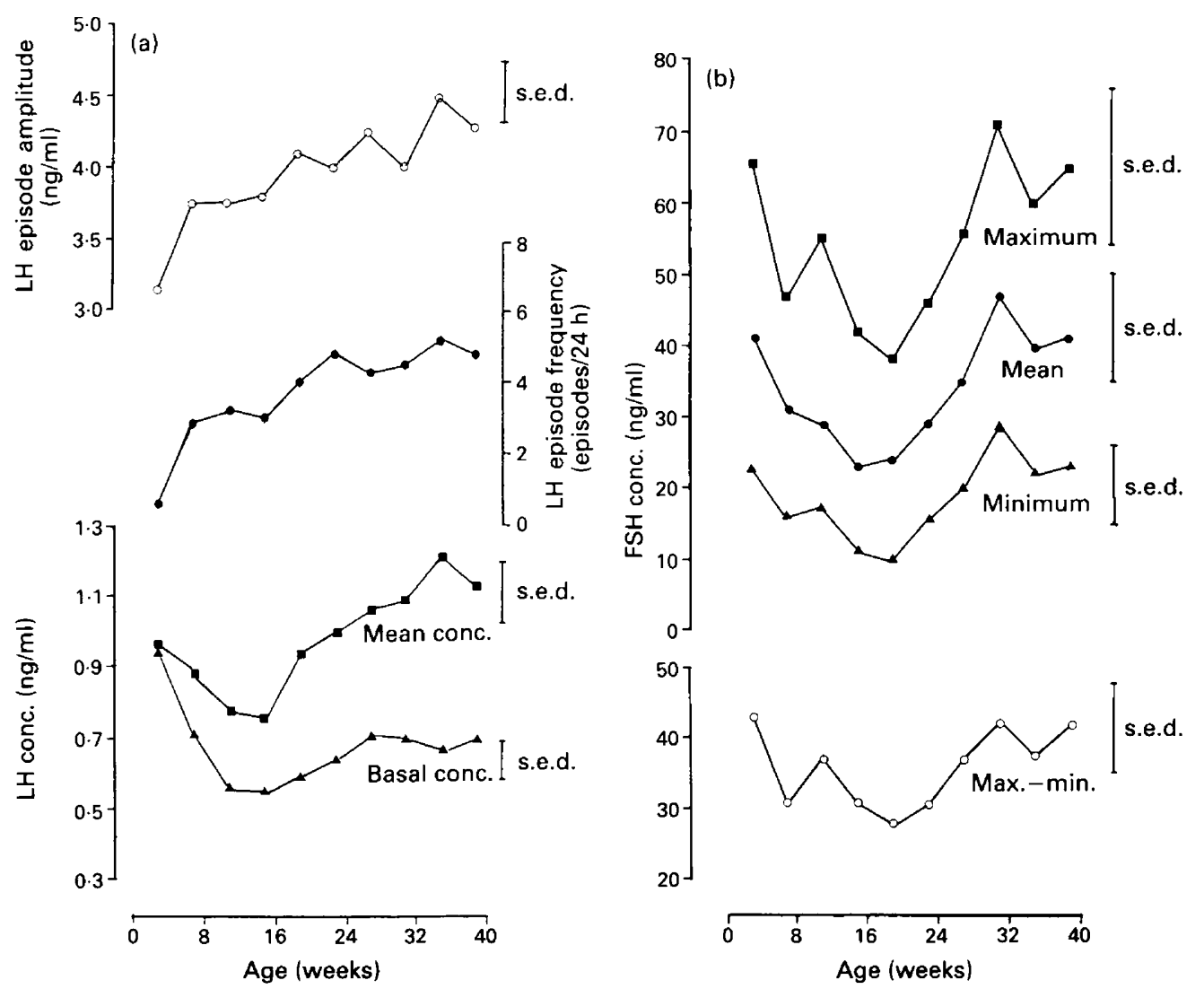

Fig. 2. Changes in characteristics of (a) LH and (b) FSH from 24-h sampling periods of 12 heifers, sampled at monthly intervals from 3 to 39 weeks of age. Each value represents the mean of 12 heifers; a single mean value for each parameter was derived from each $24-\mathrm{h}$ sampling period for every heifer and used in the derivation of the overall group mean. The appropriate s.e.d. for comparing monthy means is shown by the appropriate error bar for each parameter.

of age to $23.4 \mathrm{ng} / \mathrm{ml}$ by 15 weeks of age, then increasing from $23.6 \mathrm{ng} / \mathrm{ml}$ at 19 weeks of age to $41 \cdot 1 \mathrm{ng} / \mathrm{ml}$ by 35 weeks of age. FSH concentrations fluctuated rapidly within each 24 -h sampling period, unlike the clearly episodic release of LH (see Figs 4(i) and 4(ii)). To characterize these fluctuations, 4-h maximum and minimum FSH concentrations within a 24-h period were averaged for each animal (Fig. 2b). Maximum and minimum FSH concentrations both showed significant quadratic $(P<0.01)$ trends, both decreasing between 3 and 19 weeks of age followed by an increase to 31 weeks of age. The difference between maximum and minimum FSH values also showed a quadratic $(P<0.01)$ pattern of change and was least between 19 and 23 weeks of age, and largest at 3 and 35 weeks of age (Fig. 2b).

Mean gonadotrophin concentrations were also estimated from the single, weekly samples. These results are shown in Fig. 3 with the mean gonadotrophin concentrations estimated from the intensive sampling periods. Due to the large degree of variation between animals, no significant change in mean $\mathrm{LH}$ concentration was apparent using a weekly sampling regimen, but there was a trend for the weekly mean $\mathrm{LH}$ values to decline from birth to about 24 weeks of age, before increasing gradually up to the time of puberty. Weekly sampling revealed a significant, largely quadratic $(P<0.001)$ change in mean FSH levels between birth and 39 weeks of age; mean FSH concentrations decreased from approximately 7 weeks of age to reach a nadir around 23 weeks, thereafter increasing to 39 weeks of age (Fig. 3b). 

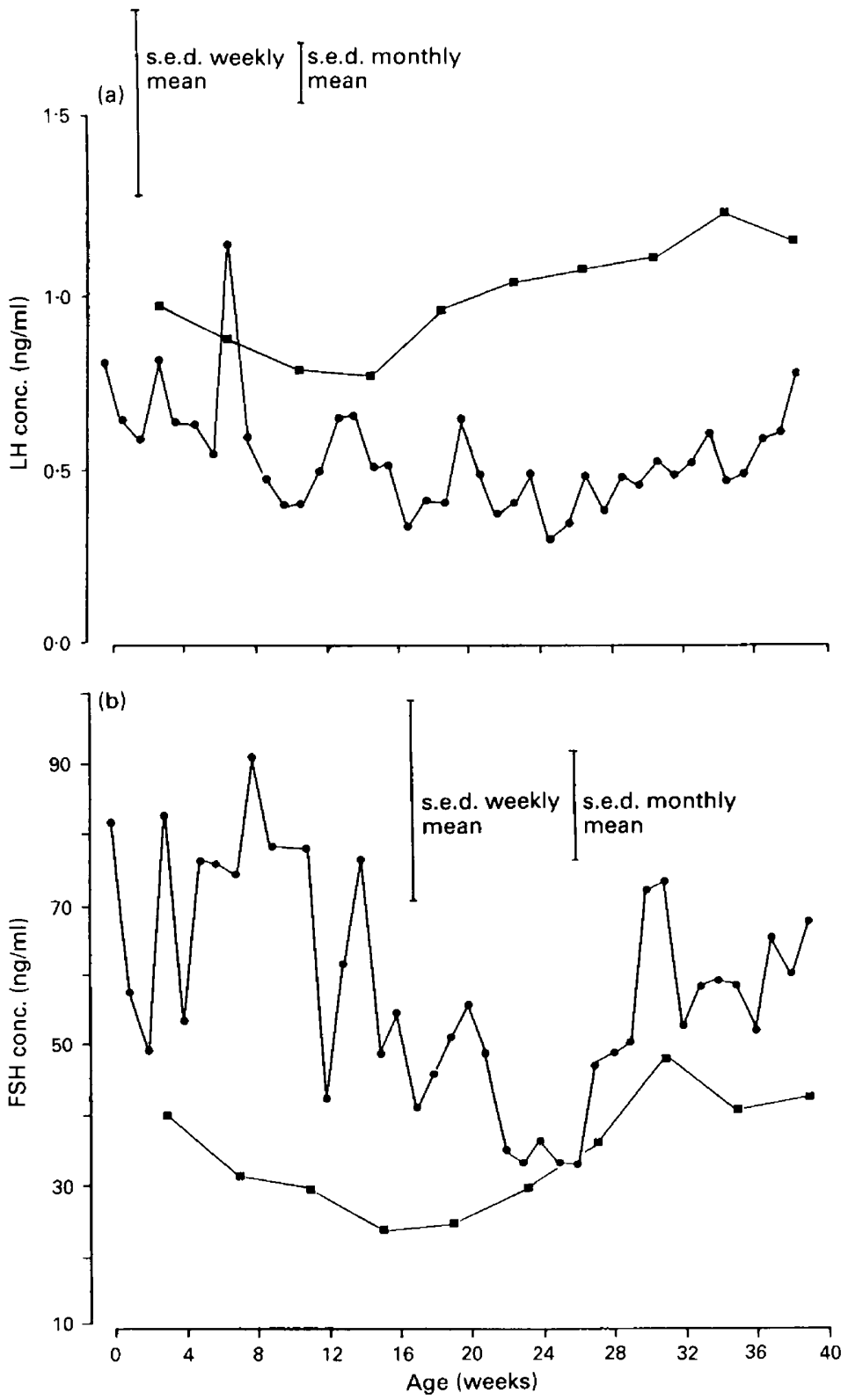

Fig. 3. Mean plasma concentrations of (a) LH and (b) FSH from 12 heifers from birth to 39 weeks of age. Each weekly value is the mean of a single sample taken from each heifer. Data obtained from weekly sampling (O) are shown alongside those obtained from frequent sampling at monthly intervals ( $\boldsymbol{\square})$ and the respective s.e.d. values for comparing weekly or monthly values are indicated.

The two sampling regimens showed significantly different changes in plasma gonadotrophin concentrations over the prepubertal period (LH, $P<0.001$; FSH, $P<0.01$ ). Weekly mean LH concentrations were lower than those calculated from intensive sampling, while mean FSH concentrations were overestimated by weekly sampling. 


\section{Gonadotrophin concentrations before puberty}

Based on LH profiles derived from 24-h sampling periods in individual animals over the duration of the experiment, it was apparent that 8 -h bleeds gave a poor estimate of $\mathrm{LH}$ episode frequency per $24 \mathrm{~h}$ until LH episode frequency became $\geqslant 4$ episodes $/ 8 \mathrm{~h}$. This was because until that time LH episodes occurred at very irregular intervals during a $24-\mathrm{h}$ period. This therefore precluded using data derived from 8 -h bleeds in the statistical analysis. Furthermore, since sampling periods were not synchronous about first ovulation, different animals had to be compared directly on a daily basis causing severe statistical problems. To help overcome this problem, gonadotrophin data from monthly bleeds were divided into periods of approximately 5 days, relative to the day of first ovulation (Day 0), and are expressed in Fig. 5 as means \pm s.e.m.

Representative LH profiles from individual heifers about puberty are also shown in Fig. 4(i). No marked change in mean plasma LH concentrations was observed immediately before first ovulation (Day 0), although they did decrease from an overall mean value of $1.2 \pm 0.08 \mathrm{ng} / \mathrm{ml}$ for the 30 days preceding to $0.9 \pm 0.06 \mathrm{ng} / \mathrm{ml}$ over the 7 days after this first presumed ovulation (Fig. 5).

Although LH episode frequency did not apparently increase before first ovulation, it decreased from $7 \pm 1.0$ episodes $/ 24 \mathrm{~h}$ over the 30 days before to $1 \pm 1.0$ episodes $/ 24 \mathrm{~h}$ during the 7 days after first ovulation (Figs 4(i) and 5).

The amplitude of $\mathrm{LH}$ episodes showed no change over the immediate prepubertal period (Fig. 5).

Representative FSH profiles from individual heifers, relative to first ovulation are illustrated in Fig. 4(ii). No change in mean FSH concentration could be associated with the onset of oestrous cycles in these heifers.

Mean gonadotrophin concentrations derived from weekly sampling were synchronized relative to puberty, with the last sample taken either on or before the day of first presumed ovulation (Week 0 ). Data were then analysed over the 14 weeks before and 4 weeks after Week 0 (Fig. 6). Weekly mean LH concentrations increased significantly during the 2 weeks before first presumed ovulation, producing both linear $(P<0.001)$ and quadratic $(P<0.05)$ trends within the data. Mean LH concentrations then decreased after Week 0 . Analysis of weekly FSH values revealed no significant changes in FSH concentrations around the time of first ovulation (Fig. 6).

\section{Discussion}

Many previous attempts to characterize gonadotrophin secretion in the prepubertal animal have relied on short periods (up to $8 \mathrm{~h}$ ) of intensive sampling, or on single blood samples. It was apparent from the present study that 8 -h periods of $15-\mathrm{min}$ sampling give an unreliable estimation of LH episode frequency, and therefore of mean LH concentration, when compared to the value obtained from longer (24-h) sampling periods, at least until LH episode frequency reached a rate of $\geqslant 4$ episodes $/ 8 \mathrm{~h}$. Using individual 24 - $\mathrm{h}$ profile bleeds it was apparent that the episode frequency determined from an 8 - $h$ portion of a profile could vary from 0 to 9 episodes $/ 24 \mathrm{~h}$. The number generally depended upon which 8-h portion was used. Such variation precluded the use of the 8-h profiles from incorporation in the overall analysis of the data. Similarly, weekly blood sampling gave a poor estimate of overall mean LH concentrations, and no insight into changes in the components of gonadotrophin secretion. Since LH episode frequency was low during most sampling periods in this study, it is probable that most weekly samples were taken when LH concentrations were basal, thus accounting for the lower mean LH concentrations estimated from these samples, compared to the values derived from intensive sampling. Hence, when episode frequency is low, a single sample is a better indicator of basal $\mathrm{LH}$ concentration than of overall mean $\mathrm{LH}$ concentrations.

FSH concentrations fluctuated rapidly within a 24-h sampling period, in contrast to the well defined episodic release of LH. FSH values were high immediately after birth, fell to a nadir and 


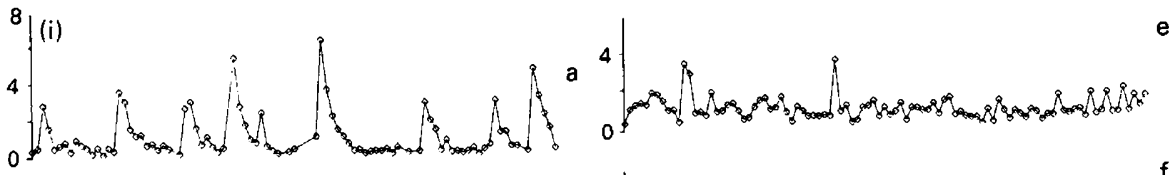
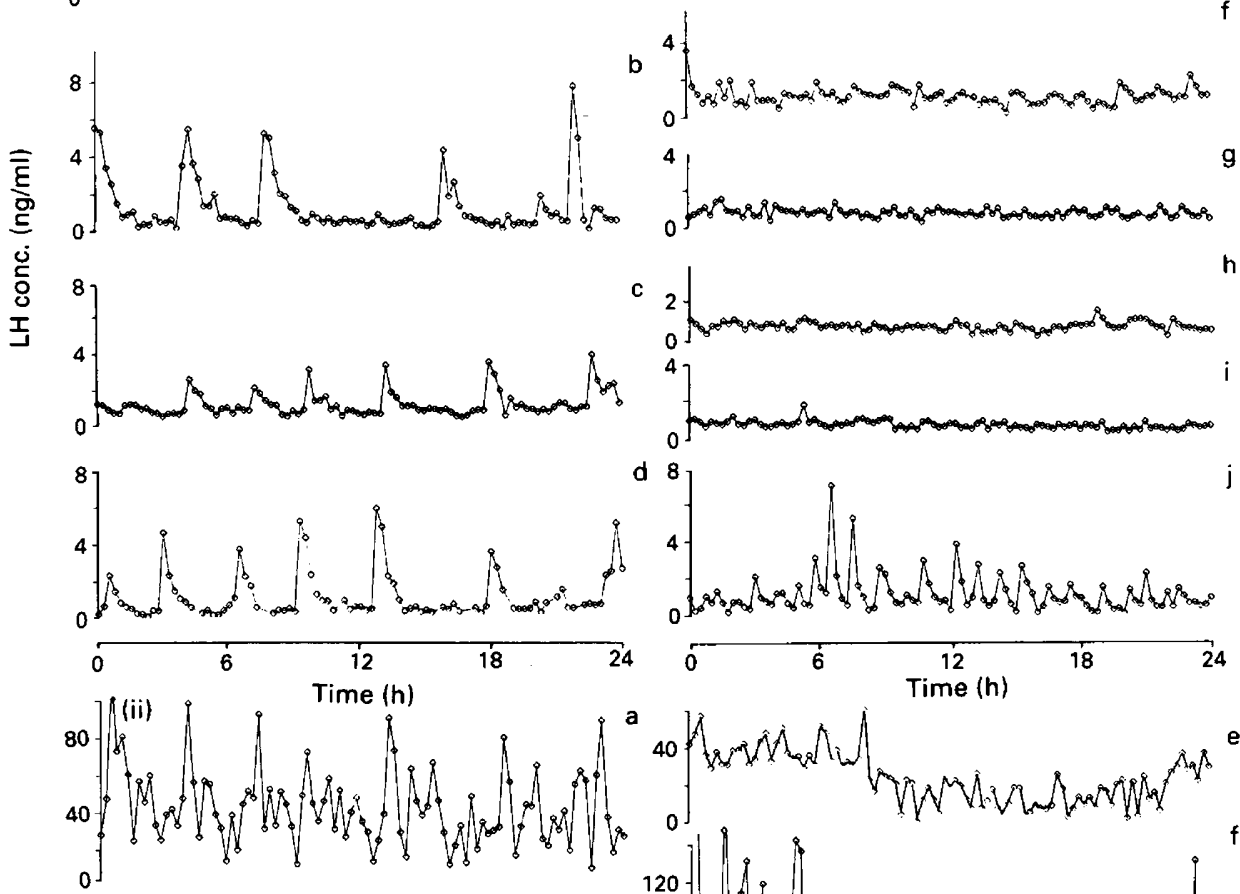

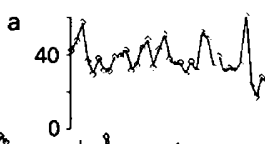

Time (h)

f

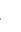
h

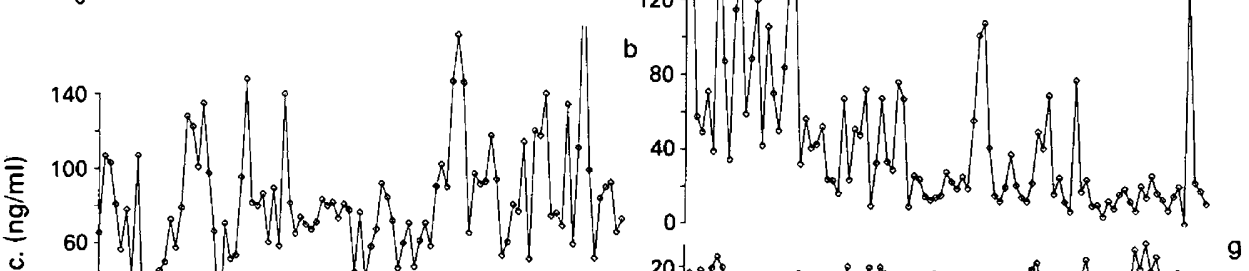

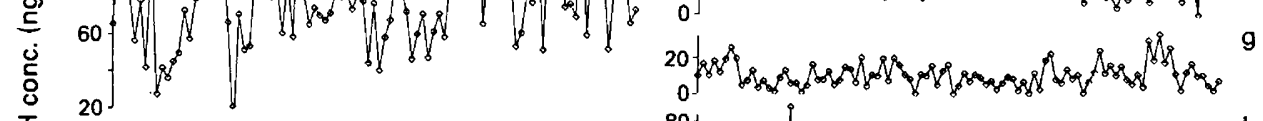

韷

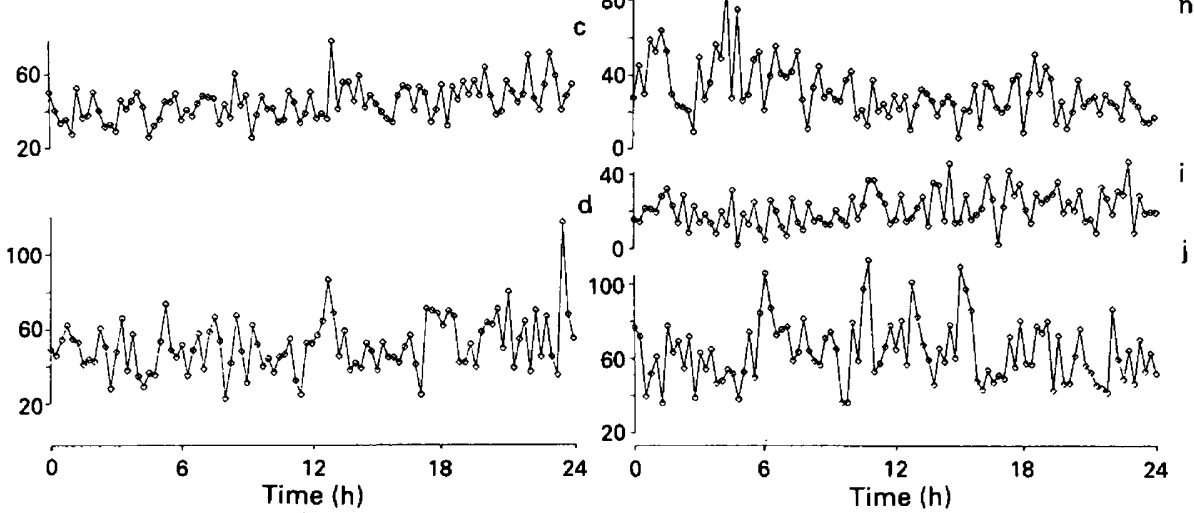

Fig. 4. Plasma LH (i) and plasma FSH (ii) profiles from individual heifers relative to the time of first ovulation; (a) 6 days before first ovulation, (b) 5 days before first ovulation, (c) 3 days before first ovulation, (d) 2 days before first ovulation, (e) 2 days after first ovulation (f) 4 days after first ovulation, (g) 5 days after first ovulation, (h) 6 days after first ovulation, (i) 4 days after first oestrus, and (j) 2 days before second oestrus. 


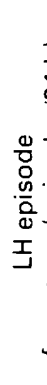
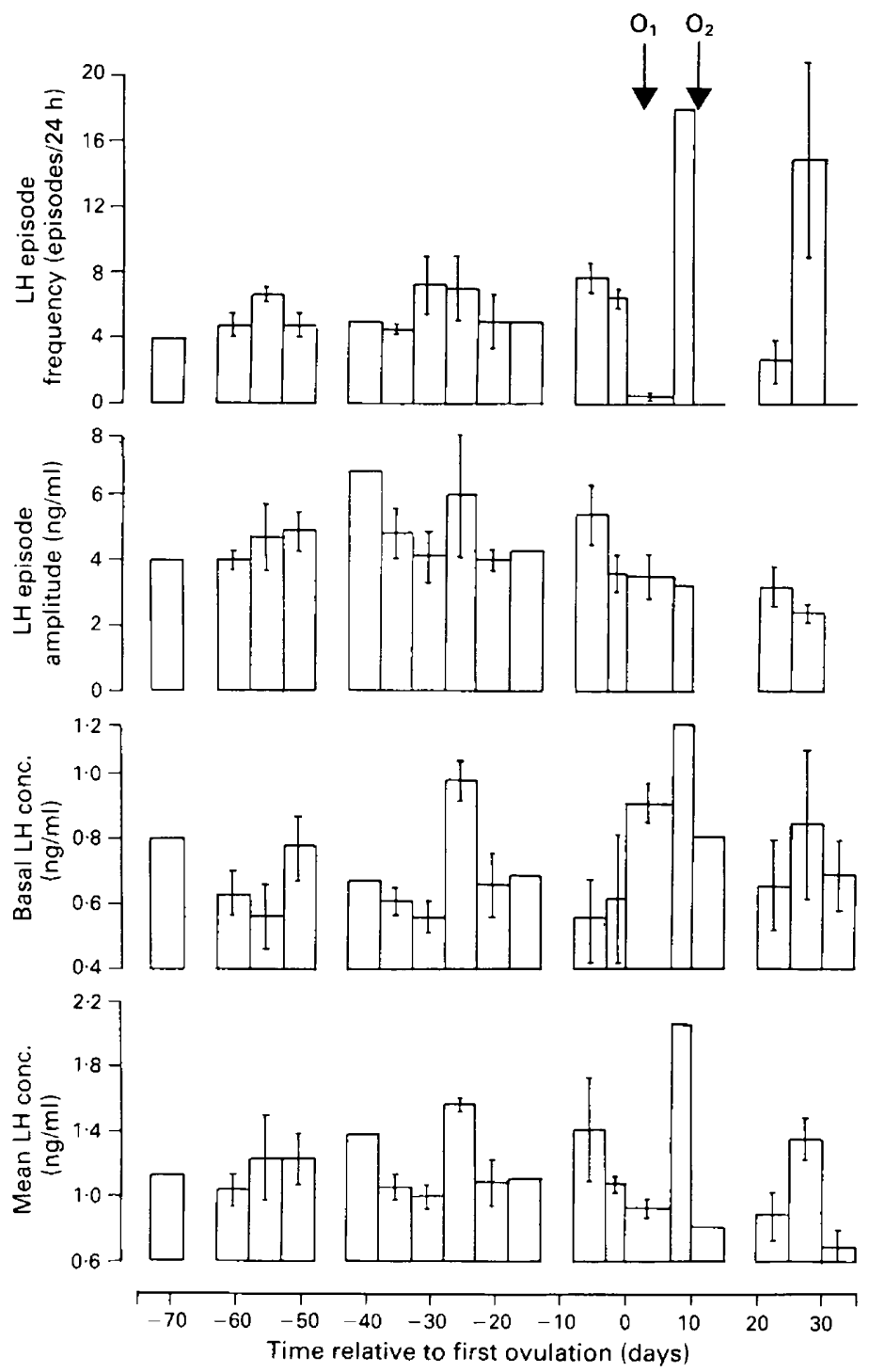

Fig. 5. Mean ( \pm s.e.m.) plasma LH data obtained from 24-h sampling periods of 12 heifers relative to the time of first ovulation. $\mathrm{O}_{1}=$ first ovulation; $\mathrm{O}_{2}=$ second ovulation.

then increased. The timing of this nadir was dependent upon the sampling method employed. Using average maximum and minimum FSH concentrations over 24-h sampling periods, it became apparent that the smallest fluctuations in FSH values occurred at 23 weeks of age, coincident with the nadir observed from weekly sampling. Therefore, weekly sampling is a better estimate of the variation in FSH concentrations, than of changes in actual FSH concentrations. These data clearly illustrate the need for extended periods of frequent sampling to monitor accurately gonadotrophin secretion in the prepubertal animal, and seriously question the conclusions which are derived from more limited data.

The initial fall in mean $\mathrm{LH}$ values which was evident from weekly and monthly sampling was largely a reflection of changes in basal LH concentrations. However, the subsequent increase in mean concentration from 15 weeks of age was largely due to an increase in LH episode frequency 


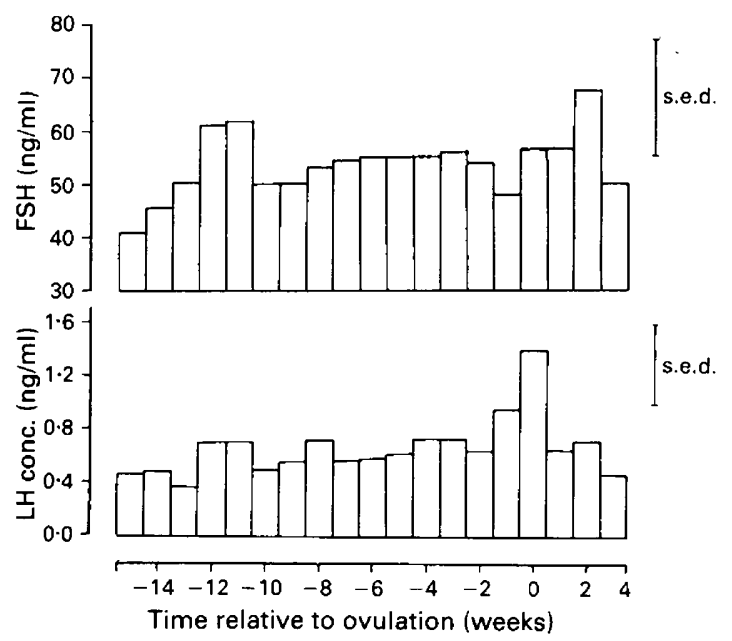

Fig. 6. Mean plasma LH and FSH concentrations obtained from weekly sampling of 12 heifers before and after first ovulation. The respective s.e.d. values for comparing any 2 means are indicated.

and, therefore, was not apparent from weekly sampling. Many reports for lambs and heifers suggest that post-natal gonadotrophin concentrations are low. Such discrepancies are unlikely to result from different sampling regimens since they were seen with both sampling frequencies in this study. It is possible that they are due to seasonal factors which can influence the pattern of gonadotrophin secretion after birth in the lamb (Fitzgerald \& Butler, 1982) and the heifer (Moseley et al., 1984). In both species, LH concentrations are reported to be higher in the neonate born in autumn than in those born in spring (Schams et al., 1981; Fitzgerald \& Butler, 1982; Schillo et al., 1983; Moseley et al., 1984). Such influences may be the result of seasonal differences in management and rearing. Despite a seasonal involvement in FSH release in the lamb, no effect was seen in this study. Indeed, temporal changes in FSH concentrations of these autumn-born heifers were comparable to those of spring-born heifers in the study of Schams et al. (1981).

Reports of an episodic pattern of LH release developing during the first month of life in the lamb (Foster et al., 1975), the heifer (Schams et al., 1981) and the bull (Amann \& Walker, 1983) are supported by this study. However, the large degree of between-animal variation in the frequency of episodic release, and in the time at which it was initiated, indicate a maturational change during this period. Initially LH episode frequency and amplitude increased as mean and basal LH concentrations decreased. However, after 15 weeks of age, mean LH values increased, paralleling $\mathrm{LH}$ episode frequency and amplitude. These changes in mean $\mathrm{LH}$ concentrations could reflect the initial development of an inhibitory mechanism controlling gonadotrophin secretion, followed by a gradual escape from inhibition. Nevertheless, when puberty was relatively close, LH episode frequency was still far less than that reported during the follicular phase of the adult heifer, a frequency known to be important in promoting the final stages of follicle maturation before ovulation (Rahe et al., 1980).

A progesterone elevation of short duration, and comparable with that previously reported for the lamb (Berardinelli et al., 1980) and heifer (Gonzalez-Padilla et al., 1975a; Berardinelli et al., 1979), was observed before first oestrus in all but 2 heifers. In these individuals the sampling frequency was probably increased too late to detect it. Evidence from short cycles after periods of anovulation in the sheep indicate that this transient progesterone rise is produced after the ovulation of an immature follicle which responds poorly to the preovulatory gonadotrophin surge (Hunter et al., 1986). A similar occurrence may well exist in the heifer during the transition to cyclic 
activity at puberty. In every heifer, this abnormal luteal phase was followed immediately by normal cyclic activity. It is proposed that the progesterone produced by this abnormal structure was sufficient to synchronize follicular development and ensure that the second preovulatory gonadotrophin surge occurred at the optimal time relative to preovulatory follicle development.

Collection of data immediately before first ovulation is difficult since there is no indication that puberty is about to occur. This has led to much speculation about the events leading to first ovulation. It is generally assumed that the first ovulation is stimulated by an increase in LH episode frequency, since ovulation may be induced in prepubertal animals by repeated administration of low doses of GnRH or LH for $72 \mathrm{~h}$, creating an 'artificial follicular phase' (Foster et al., 1984; McLeod et al., 1985; Skaggs et al., 1986). In this study, hormonal events around puberty were synchronized retrospectively, according to progesterone data and, therefore, the times of first ovulation are not precise. Another problem in identifying changes in gonadotrophin secretion immediately before puberty was the monthly interval between sampling periods in these heifers. Different animals were compared on a daily basis around puberty and the resulting between-animal variation may have masked subtle changes in gonadotrophin secretion. It is therefore probable that any short-lived increase in LH episode frequency in most heifers would have been missed. Weekly sampling was not subject to such problems and showed an abrupt increase in LH secretion just before first ovulation. As already discussed, single blood samples are likely to give a better estimation of mean LH concentration when LH episode frequency is high, supporting the view that an abrupt increase in episodic LH release is the major stimulus for first ovulation. In contrast, no change in FSH secretion was evident before first ovulation, suggesting that FSH has a more permissive role than that of LH. Furthermore, ovulation may be induced in prepubertal lambs by injection of LH alone, suggesting that a required threshold level of FSH is already present (Foster et al., 1984). FSH concentrations decreased several months before puberty in this as in other studies (Gonzalez-Padilla et al., 1975a; Schillo et al., 1983), possibly due to rising levels of inhibin and/or oestradiol from developing follicles, and a general increase in ovarian activity at this time.

The mechanism whereby the first ovulation is stimulated is still uncertain. Gonadotrophin concentrations decreased in the present study during the neonatal period, possibly reflecting an increase in sensitivity of $\mathrm{GnRH}$ secretion to the inhibitory effects of ovarian steroids. From 15 weeks of age gonadotrophin concentrations gradually increased, possibly due to a gradual decrease in sensitivity to ovarian steroid inhibitory feedback. The 'gonadostat' hypothesis proposes that GnRH release 'escapes' from oestradiol inhibition at puberty. However, studies of the female rat indicate that concentrations of oestradiol which suppress the increase in gonadotrophin concentrations after ovariectomy in the prepubertal animal are equally effective after puberty when used in combination with progesterone (Andrews et al., 1981). These data suggest that a requirement for progesterone develops at puberty, rather than a decrease in the inhibitory effects of oestradiol. In the cow, a combination of progesterone and oestradiol are also required to restore gonadotrophin concentrations following ovariectomy (Beck et al., 1976). Furthermore, it has been demonstrated in the rat that the resetting of the gonadostat follows the first preovulatory surge and is therefore a consequence of, rather than a cause of puberty (Andrews et al., 1981). This may also be the case in the heifer, but it is evident that neither the preovulatory gonadotrophin surge, the increase in oestradiol before, nor the increase in progesterone after ovulation initiate this change in sensitivity to ovarian steroids. All of these situations have been artificially induced in the prepubertal heifer but none is followed by puberty (Gonzalez-Padilla et al., 1975b; Barnes et al., 1980; McLeod et al., 1985; Skaggs et al., 1986). Puberty has been induced in heifers, close to the natural age of cyclicity, by simulating changes in oestradiol and progesterone normally seen at puberty in the heifer, although this treatment was ineffective in younger animals (Gonzalez-Padilla et al., 1975c). It is therefore postulated that the central mechanisms controlling the cyclic release of gonadotrophins are not responsive to ovarian steroids until just before the onset of puberty. Consequently, puberty awaits the final maturation of some central component regulating gonadotrophin secretion, and this is supported by the abruptness with which the stimulus for ovulation developed in this study. 
We thank the A.F.R.C. for financial support and NIAMKDD, Bethesda, U.S.A. for standard LH and FSH preparations.

\section{References}

Amann, R.P. \& Walker, O.J. (1983) Changes in the pituitary-gonadal axis associated with puberty in Holstein bulls. J. Anim. Sci. 57, 433-442.

Andrews, W.W., Advis, J.P. \& Ojeda, S.R. (1981) The maturation of estradiol-negative feedback in female rats: evidence that the resetting of the hypothalamic 'gonadostat' does not precede the first preovulatory surge of gonadotropins. Endocrinology 109, 2022-2031.

Barnes, M.A., Bierley, S.T., Halman, R.D. \& Henricks, D.M. (1980) Follicle stimulating hormone, luteinizing hormone and estradiol-17B response in GnRH treated prepubertal Holstein heifers. Biol. Reprod. 22, 459-465.

Beck, T.W., Smith, V.G., Seguin, B.E. \& Convey, E.M. (1976) Bovine serum LH, GH and prolactin following chronic implantation of ovarian steroids and subsequent ovariectomy. J. Anim. Sci. 42, 461-468.

Berardinelli, J.G., Dailey, R.A., Butcher, R.L. \& Inskeep, E.K. (1979) Source of progesterone prior to puberty in beef heifers. J. Anim. Sci. 49, 1276-1280.

Berardinelli, J.G., Dailey, R.A., Butcher, R.L. \& Inskeep, E.K. (1980) Source of circulating progesterone in prepubertal ewes. Biol. Reprod. 22, 233-236.

Day, M.L., Imakawa, K., Garcia-Winder, M., Zalesky, D.D., Schanbacher, B.D., Kittok, R.J. \& Kinder, J.E. (1984) Endocrine mechanisms of puberty in heifers: estradiol negative feedback regulation of luteinizing hormone secretion. Biol. Reprod. 31, 332-341.

Fitzgerald, J. \& Butler, W.R. (1982) Seasonal effects and hormonal patterns related to puberty in ewe lambs. Biol. Reprod. 27, 853-863.

Foster, D.L., Lemons, J.A., Jaffe, R.B. \& Niswender, G.D. (1975) Sequential patterns of circulating luteinizing hormone and follicle-stimulating hormone in the female sheep from early postnatal life through the first estrous cycles. Endocrinology 97, 985-994.

Foster, D.L. \& Ryan, K.D. (1979) Endocrine mechanisms governing transition into adulthood: a marked decrease in inhibitory feedback action of estradiol on tonic secretion of luteinizing hormone in the lamb during puberty. Endocrinology 105, 896-904.

Foster, D.L., Ryan, K.D. \& Papkofi, H. (1984) Hourly administration of luteinizing hormone induces ovulation in prepubertal female sheep. Endocrinology 115, 1179-1185.

Gonzalez-Padilla, E., Wiltbank, J.N. \& Niswender, G.D. (1975a) Puberty in beef heifers. I The interrelationship between pituitary, hypothalamic and ovarian hormones. J. Anim. Sci. 40, 1091-1104.

Gonzalez-Padilla, E., Niswender, G.D. \& Wiltbank, J.N. (1975b) Puberty in beef heifers. II Effect of injections of progesterone and estradiol-17 $\beta$ on serum LH, FSH and ovarian activity. J. Anim. Sci. 40, 1105-1109.

Gonzalez-Padilla, E., Ruiz, R., Lefever, D., Denham, A. \& Wiltbank, J.N. (1975c) Puberty in beef heifers. III
Induction of fertile estrus. J. Anim. Sci. 40, $1110-1118$

Hunter, M.G., Southee, J.A., McLeod, B.J. \& Haresign, W. (1986) Progesterone pretreatment has a direct effect on GnRH-induced preovulatory follicles to determine their ability to develop into normal corpora lutea in anoestrous ewes. J. Reprod. Fert. 76, 349-363.

McLeod, B.J., Haresign, W., Peters, A.R. \& Lamming, G.E. (1984) Plasma LH and FSH concentrations in prepubertal beef heifers before and in response to repeated injections of low doses of GnRH. J. Reprod. Fert. 70, 137-144.

McLeod, B.J., Peters, A.R., Haresign, W. \& Lamming, G.E. (1985) Plasma LH and FSH responses and ovarian activity in prepubertal heifers treated with repeated injections of low doses of GnRH for $72 \mathrm{~h} . J$. Reprod. Fert. 74, 589-596.

Moseley, W.M., Dunn, T.G., Kaltenbach, C.C., Short, R.E. \& Staigmiller, R.B. (1984) Negative feedback control of luteinizing hormone secretion in prepubertal beef heifers at 60 and 200 days of age. J. Anim. Sci. 58, 145-150.

Rahe, C.H., Owens, R.E., Fleeger, J.L., Newton, H.J. \& Harmes, P.G. (1980) Pattern of plasma luteinizing hormone in the cyclic cow: dependence upon the period of the cycle. Endocrinology 107, 498-503.

Ramirez, V.D. \& McCann, S.M. (1963) Comparison of the regulation of luteinizing hormone secretion in immature and adult rats. Endocrinology 72, 452-464.

Robinson, T.J. (1977) Reproduction in cattle. In Reproduction in Domestic Animals, pp. 433-454. Eds H. H. Cole \& P. T. Cupps. Academic Press, New York.

Sawyer, G.J. \& Fulkerson, W.J. (1981) The effectiveness of steers and heifers treated with oestrogen or testosterone to detect oestrus in cattle. Anim. Reprod. Sci. 3, 259-269.

Schams, D., Schallenberger, E., Gombe, S. \& Karg, H. (198I) Endocrine patterns associated with puberty in male and female cattle. J. Reprod. Fert., Suppl. 30, 103-110.

Schillo, K.K., Hansen, P.J., Kamwanja, L.A., Dierschke, D.J. \& Hauser, E.R. (1983) Influence of season on sexual development in heifers: Age at puberty as related to growth and serum concentrations of gonadotropins, prolactin, thyroxine and progesterone. Biol. Reprod. 28, 329-341.

Skaggs, C.L., Able, B.V. \& Stevenson, J.S. (1986) Pulsatile or continuous infusion of luteinizing hormonereleasing hormone and hormonal concentrations in prepubertal beef heifers. J. Anim. Sci. 62, 1034-1048.

Steel, R. E. \& Weisz, J. (1974) Changes in the sensitivity of estradiol-LH feedback system with puberty in the female rat. Endocrinology 95, 513-520.

Webb, R., Lamming, G.E., Haynes, N.B., Hafs, H.D. \& Manns, J.G. (1977) Response of cyclic and post- 
partum suckled cows to injections of synthetic LHRH. J. Reprod. Fert. 50, 203-210.

Webb, R., Lamming, G.E., Haynes, N.B. \& Foxcroft,

G.R. (1980) Plasma progesterone and gonadotrophin concentrations and ovarian activity in post partum dairy cows. J. Reprod. Fert. 59, 133-143.

Received 19 May 1987 